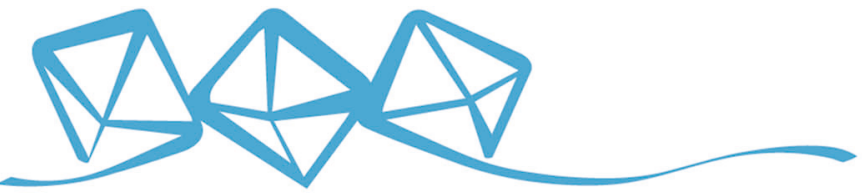 COMMUNICATIONS MATERIALS
}

ARTICLE

https://doi.org/10.1038/s43246-020-00113-y

OPEN

\section{Microstructural degradation during the storage of biomass pellets}

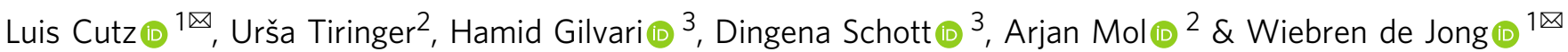

The use of biomass pellets as a source of renewable energy has increased in recent times. However, pellet storage during transportation can compromise their properties, due to fluctuating temperature and humid environments. Here, we show that extended storage of one month at $40{ }^{\circ} \mathrm{C}$ and $85 \%$ relative humidity causes significant biomass pellet degradation. This was evidenced by higher pellet porosity, weight gain, increased inclusion body formation and creation of an internal network of cracks. We quantify the inclusion and pore growth processes at the surface and within the pellets, which has implications for subsequent thermochemical conversion. The global bioenergy transition may depend upon biomass pellets, and this study shows that storage conditions are critical in the supply chain, so to maintain their quality. Without the development of stronger policies to avoid premature degradation of biomass pellets, they may not realize their full potential as a bioenergy source.

\footnotetext{
${ }^{1}$ Section of Large-Scale Energy Storage (LSE), Department of Process \& Energy, Faculty of Mechanical, Maritime and Materials Engineering, Delft University of Technology, Delft, The Netherlands. ${ }^{2}$ Section of Corrosion Technology and Electrochemistry, Department of Materials Science and Engineering, Faculty of Mechanical, Maritime and Materials Engineering, Delft University of Technology, Delft, The Netherlands. ${ }^{3}$ Section of Transport Engineering and Logistics, Department of Maritime \& Transport Technology, Faculty of Mechanical, Maritime and Materials Engineering, Delft University of Technology, Delft, The

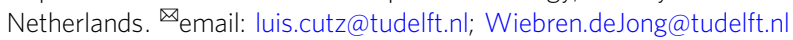


$\mathrm{T}$ he use of biomass as a renewable fuel has increased sharply during the last decade as a result of the concern of high anthropogenic emissions ${ }^{1}$. However, due to the challenges in establishing sustainable supply chains for biomass, its heterogeneity, and the inherent physicochemical properties of biomass feedstock, such as low bulk density and high moisture content, biomass implementation has not grown as originally anticipated ${ }^{2,3}$. To overcome these challenges and to make raw biomass easier to handle, pretreatment processes and pelletization are used to improve its quality for later use in residential heating, large-scale electricity generation and as renewable carbon feedstock for the chemical industry ${ }^{4}$. However, many countries do not have a large potential of biomass resources or have only marginal land available for biomass production, which has rocked the global biomass pellet market and trade (Fig. 1).

A considerable amount of the overall global consumption of pellets are traded from the Americas to Europe and Asia, around one third in $2018^{5}$. In 2018 the global demand of pellets for heating and industrial purposes totalled 34 million tonnes and it is expected to increase to around 69 million tonnes, by $2025^{6}$. Depending on the transportation type, transport distance and storage conditions, biomass pellets are being stored for a period from up to one week or to three months in a fluctuating temperature and humidity environment ${ }^{7}$. Storage during extended periods of time, especially at high temperatures ${ }^{8-11}$, accelerates the degradation of pellets, reducing the quality of the fuel and consequently the fuel conversion behavior ${ }^{12}$. Recently, coupling advanced pretreatment processes ${ }^{4}$, such as torrefaction with pelletization, have opened new frontiers to enhance the physicochemical properties of raw biomass to stand the current environmental conditions during transport and storage ${ }^{4,13}$. However, similar problems as those observed in untreated biomass pellets, such as particle breakage and moisture-induced damage, are still present during logistics of torrefied pellets, leading to structural degradation ${ }^{13}$. Biomass degradation, especially when dealing with large volume of pellets, can lead to selfheating, spontaneous combustion, pellet attrition, equipment fouling, and numerous health threats to workers exposed to dust particles ${ }^{9,14-17}$.

To the best of our knowledge, limited studies have focused on studying qualitatively the morphological modifications at the surface of biomass pellets ${ }^{18,19}$ and quasi in situ quantification of changes in their physicochemical properties resulting from storage $^{8,20}$. Typical investigated properties are density, chemical content (proximate and ultimate analysis), moisture sorption, mechanical strength and heating value. In the present work we provide insights on pellets degradation during storage at relatively high but possible temperature. To this end, we studied two untreated and one type of torrefied wood pellets stored in a climate chamber, during a period of one month at a constant condition of $40{ }^{\circ} \mathrm{C}$ and $85 \%$ relative humidity (RH). By the use of digital microscopy, scanning electron microscopy equipped with energy dispersive X-ray spectroscopy (SEM-EDS) and highresolution micro-computed tomography (micro-CT), we study surface, structural and chemical changes in biomass pellets, resulting from storage. We demonstrate the expansion of preexisting fractures and the growth mechanism of inclusions at the surface and inside the cracks of biomass pellets as a result of storage conditions. Ensuring the quality parameters of biomass pellets and avoiding premature degradation are crucial for increasing the adoption of biomass and to avoid costly modifications to the existing infrastructure, especially in large-scale power generation.

\section{Results and discussion}

The effect of storage conditions on the development of biomass pellet surface damage. Optical images of the three types of pellets studied before and after storage are presented in Fig. 2. Pellet surface damage is typically present in the form of cracks and damage (e.g., regions with different surface texture and color), from now on referred to as damage. The damage analysis for all nine samples is provided in Supplementary Note 3, Supplementary Fig. 1 and Supplementary Table 3.

Figure 2 illustrates that all fresh pellets already exhibit large areas of damage at the surface before being exposed to the storage conditions. Results show that after storage at $40^{\circ} \mathrm{C}$ and $85 \% \mathrm{RH}$, all biomass pellets are heavily damaged at the surface. Surface degradation due to the storage is attributed to breakage of bonds, expansion of pre-existing cracks into networks of cracks (creep damage) and de-cohesion of fibers ${ }^{21}$. After storage, the damaged area with respect to the total area of the front surface of all pellets (area ratio), increased in average by $5 \%$. Of all samples, wood pellets type II were the most affected at the surface level (Fig. 2f).

The presence of large longitudinal cracks at the pellet surface is not necessarily predictive for strength reduction as it also depends on their in-depth growth. Cracks related to pellet breakage are more likely to occur in radial direction due to the

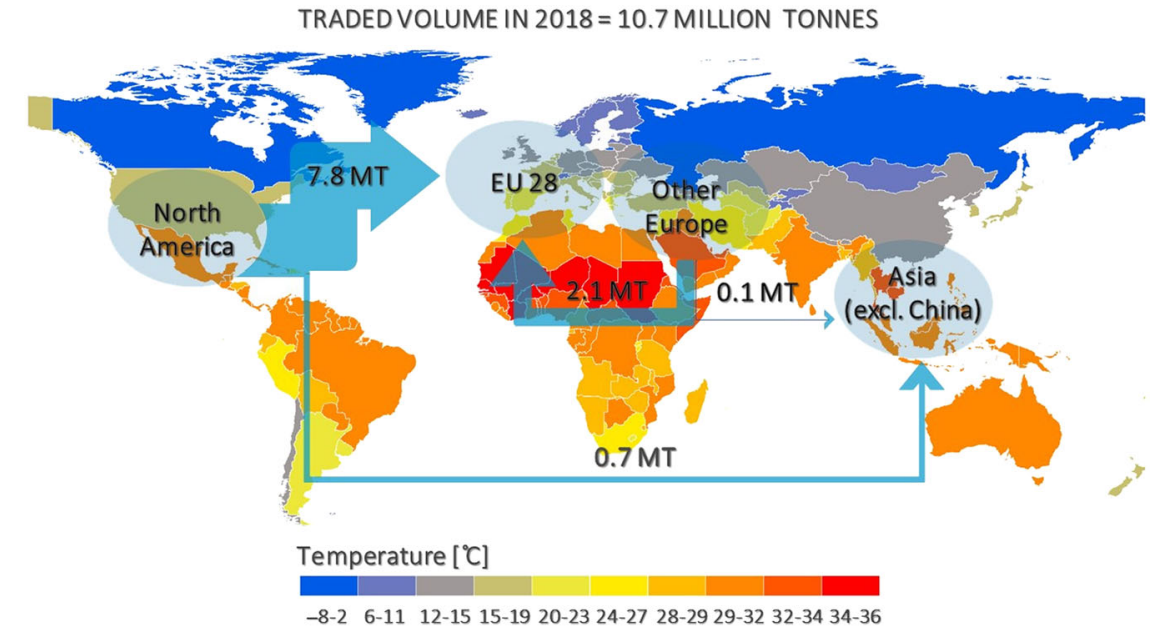

Fig. 1 Global volume of pellets traded in 2018. Light blue arrows represent the traded volume of pellets between regions. The traded volume of pellets in million tonnes was extracted from Bioenergy Europe Statistical Report ${ }^{5}$. Other Europe refers to Albania, Bosnia and Herzegovina, Belarus, Switzerland, Montenegro, Norway, Serbia, Russia, and Ukraine. Average temperature data were extracted from Climate Research Unit (CRU) ${ }^{50}$. 

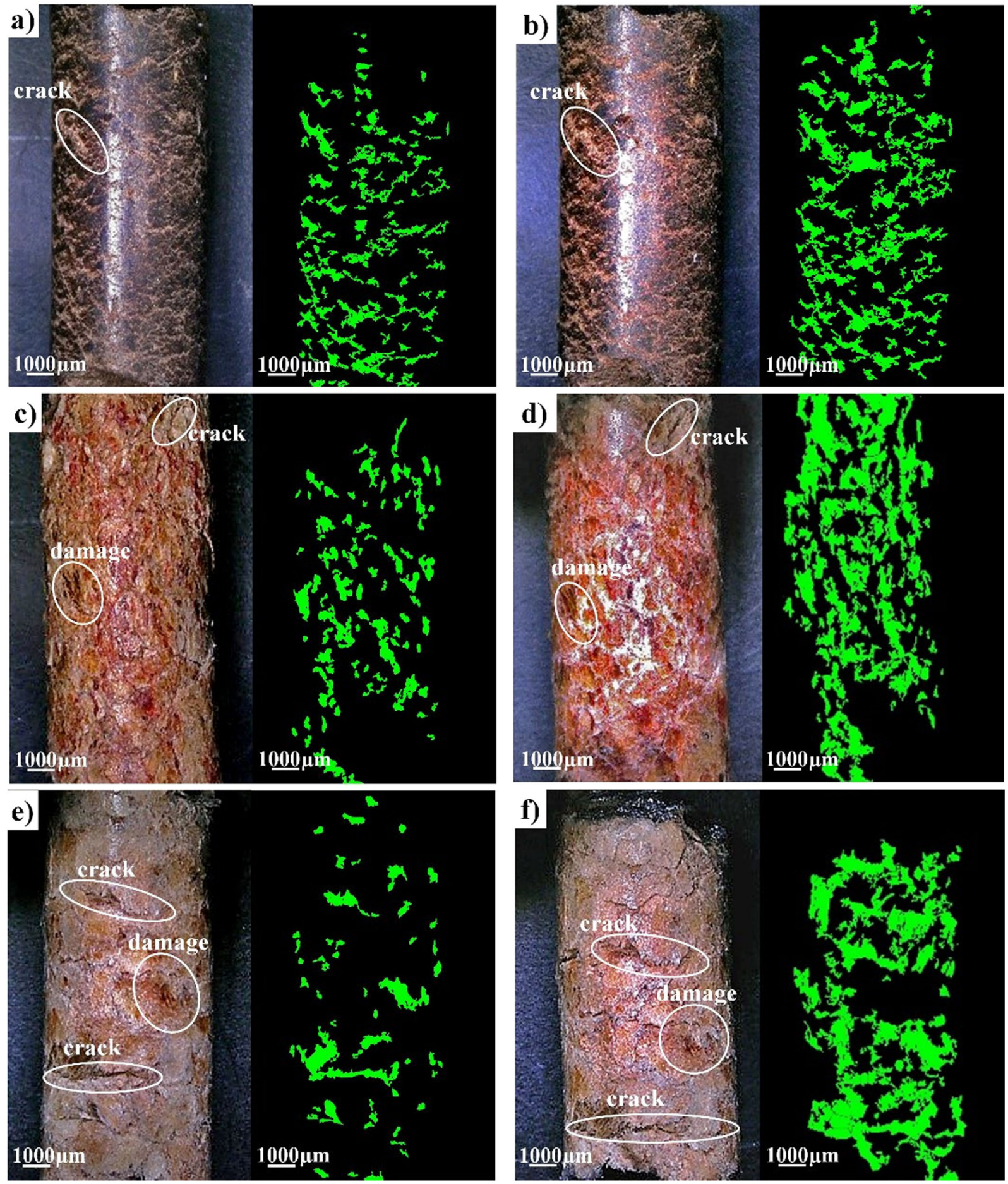

Fig. 2 Digital images and corresponded determined damage area of pellets. a, b Torrefied pellet (tor_sample3) before storage (a) and after 1 month of storage (b). c, d Wood pellet type I (wp1_sample3) before storage (c) and after 1 month of storage (d). e, f Wood pellet type II (wp2_sample3) before storage (e) and after 1 month of storage (f). Surface damage is highlighted in green.

high length-to-cross-section ratio of pellets ${ }^{9}$. Thus, to monitor the expansion of cracks, we performed a three-dimensional (3D) surface profile analysis of pellets at different storage times using digital microscopy. The mean apparent crack depth at the pellet surface before storage, 2 weeks after storage and one month after storage is provided in Fig. 3. The apparent crack depth for all evaluated samples is provided in Supplementary Fig. 2.

We found that before storage, torrefied pellets and wood pellets type II have deeper cracks compared to wood pellets type I. For example, in some torrefied samples, cracks almost reached $1 \mathrm{~mm}$ depth (Supplementary Fig. 2). Cracks start to form at the surface and the mean apparent depth of their penetration with respect to the diameter of the pellet is $9 \%$ for torrefied pellets, $7 \%$ for wood pellets type I and 9\% for wood pellets type II (Fig. 3), before storage. We found that the mean apparent crack depth decreased gradually after storage, $65 \%$ for torrefied pellets, $43 \%$ for wood pellets type I and $71 \%$ for wood pellets type II, due to pellet swelling. Results from the profile analysis do not necessarily indicate that the apparent crack depth decreased after storage, but rather imply less space between the wall fibers at the surface. 


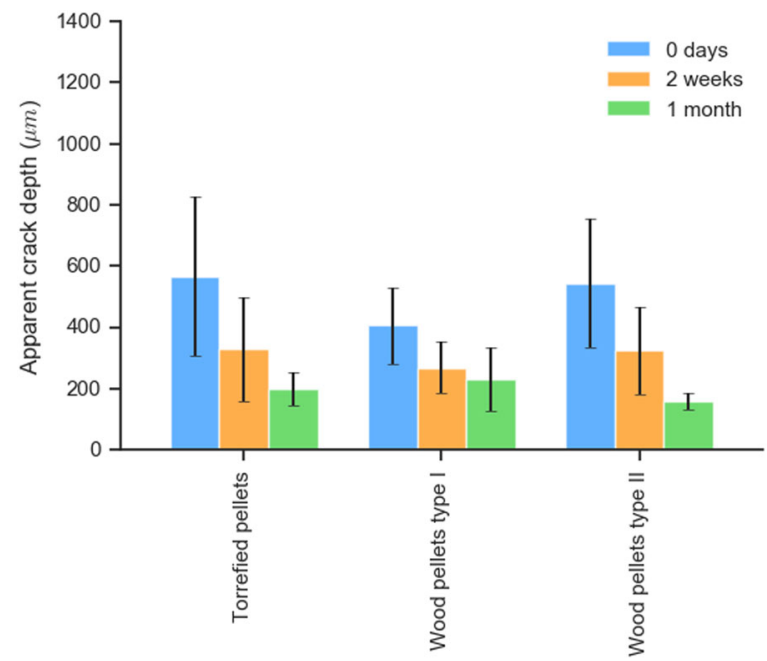

Fig. 3 Mean apparent depth of the cracks observed at the surface of biomass pellets at $\mathbf{0}$ days, $\mathbf{2}$ weeks, and $\mathbf{1}$ month after storage. Light blue, orange, and green bars represent the apparent crack depth per type of pellet in $\mu \mathrm{m}$ for 0 days, 2 weeks, and 1 month, respectively. The error bars represent the standard deviation.

The surrounding moisture fills the interstitial volume within the biomass fibers at the surface of all pellets and expands them due to moisture build-up, resulting in a mean increase of $0.4 \mathrm{~mm}$ in pellet diameter (Supplementary Table 2). Swelling of pellets is confirmed by an average pellet diameter increase of $2 \%$ for torrefied pellets, $9 \%$ for wood pellet type I and $7 \%$ for wood pellet type II, after one month of storage. A relatively small radial strain is noticed for the torrefied pellets, due to the crystalline structure of the torrefied biomass microfibrils ${ }^{4}$, which hold back the swelling. A decrease in the apparent crack depth after storage might also be attributed to increased inclusion body formation as a result of chemical reactions (e.g., oxidation) on the edge of the cracks and agglomeration within the cavities and fibre walls.

Inclusion formation at the surface and inside the cavities/ cracks of biomass pellets. We next describe the changes in morphology and elemental composition at the pellet surface, as a result of storage conditions. For simplicity, we refer to the microstructure of the pellets as "solid matrix" and all bright discernible amorphous particles as "inclusions". Inclusions comprise original inorganic-forming elements in biomass such as $\mathrm{Ca}$, $\mathrm{K}, \mathrm{Si}, \mathrm{Mg}, \mathrm{Al}, \mathrm{Fe}, \mathrm{P}, \mathrm{Cl}, \mathrm{Na}, \mathrm{Mn}$, and $\mathrm{Ti}^{22}$. Hence, inclusions also include the new minerals or phases formed during storage. Fig. 4 presents the scanning electron microscopy (SEM) imaging conducted on pellets before storage $(a, c, e)$ and after one month of storage $(b, d, f)$. Searching for an optimal way to quantify inclusions at the pellet surface after storage, we performed image analysis of each SEM image (Fig. 5). In SEM images using backscattered electron detector, elements with higher atomic number appear brighter than those with a small atomic number $^{23}$. Supplementary Note 4 provide SEM images and corresponding image analysis for all six samples, at two different surface regions, before and after storage.

SEM images confirm that at micro level, untreated or torrefied biomass pellets, have pre-existing cracks at the surface, which is in accordance with previous studies ${ }^{18}$. Pre-existing cracks are an indication of poor adhesion between adjacent fibers resulting from pelletization conditions ${ }^{12}$. After 1 month of storage, we observed changes in surface morphology and texture in all pellets due to moisture sorption (Fig. $4 \mathrm{~b}, \mathrm{~d}, \mathrm{f}$ ). This could lead to pellet abrasion $^{9}$ during handling as a result of fracture of uneven regions or detachment of small particles from pellet's surface. For wood pellet type II in particular, the ash content was relatively low (Supplementary Note 1). However, sufficient minerals existed in this type of pellet to produce a significant difference in surface morphology and texture after one month, the biggest compared to all other samples (Fig. 4f).

Increased inclusion formation has been reported in biomass harvest $^{24}$, drying ${ }^{22}$, devolatilization ${ }^{25}$, and ash storage ${ }^{26}$. Nevertheless, as far as the authors are concerned, no previous studies have quantified the formation or enlargement of inclusions neither at microscale during storage nor in any of the aforementioned stages. Inclusions are mainly observed between fibers or at the cracks located at the pellet surface (Fig. 4). Image analysis confirms inclusion growth on the pellet surface after one month of storage (Fig. 5). The mean number of inclusions in torrefied pellets increases by $80 \%$; in wood pellets type I and II by $650 \%$ and $700 \%$, respectively. Detailed analysis is provided in Supplementary Table 4-6. Despite thermal pretreatment, SEM images of torrefied pellets show similar structural pattern as untreated biomass pellets. Nevertheless, the number of inclusions detected at their surface before storage is higher than that for wood pellets due to the pretreatment method itself (Fig. 5a). Torrefaction converts a certain part of the original organic structures into new formed polymeric structures and ashes that later bind to the fiber wall ${ }^{4}$. In general, a higher number of inclusions could limit diffusion into and from the biomass pellet, affecting the transfer of the surrounding medium (e.g., oxidant) to the pellet and reducing char conversion. Similar phenomena has already been reported in combustion of poplar wood and wheat straw ${ }^{25}$.

There are four mechanisms that can explain increased inclusion formation due to storage: (M1) mineral precipitation; (M2) solid-gas chemical reactions; (M3) mineral transport through moist-softened polysaccharides; and (M4) agglomeration of inclusions. These mechanisms are further elaborated throughout the manuscript. Earlier studies on the chemical composition of biomass indicate that there is intensive mineral precipitation (M1) due to moisture evaporation after biomass harvesting ${ }^{22}$. Such mineral formations result of natural degradation could explain the increase in the number of inclusions detected at the surface of all pellets, after 1 month of storage. These minerals are in the form of in water-soluble phosphates, carbonates, sulphates, chlorides, and nitrates ${ }^{22}$. When biomass is left in the field for a prolonged time and combined with rainfall, these water-soluble salts tend to contribute to enhanced leaching of $\mathrm{Ca}, \mathrm{Cl}, \mathrm{K}, \mathrm{Mg}$, $\mathrm{Na}, \mathrm{P}$, and $\mathrm{S}^{22,24}$. Other mechanisms involved in inclusion growth (M2-M4) are linked to the inherent chemical composition of biomass and will be further explained using SEM-EDS analysis and micro-computed tomography.

Biomass is generally composed of organic (cellulose, hemicellulose, and lignin), inorganic constituents (e.g., amorphous components and minerals), and fluid matter (e.g., moisture) ${ }^{22}$. The concentrations of each constituent depend on the type of biomass, harvest practices, and environmental conditions. Furthermore, when biomass is subjected to thermochemical processes $\left(>200^{\circ} \mathrm{C}^{4}\right)$, new minerals or inorganic phases are created, commonly referred as ash ${ }^{22}$. Ash contains forming elements such as $\mathrm{Si}, \mathrm{K}, \mathrm{Na}, \mathrm{S}, \mathrm{Cl}, \mathrm{P}, \mathrm{Ca}, \mathrm{Mg}$, and Fe responsible for toxic particulate matter emissions, fouling and slagging ${ }^{14,27}$. To complement morphological changes observed in pellets, we performed EDS analysis on our samples. Fig. 6 presents the percentage change of mean elemental concentrations of region 1 and region 2, for all analyzed pellets, before storage and after one month of storage. Values presented in Fig. 6 can be interpreted as enrichment/depletion of elements with respect to the conditions before storage. The results are separated by the mean elemental 

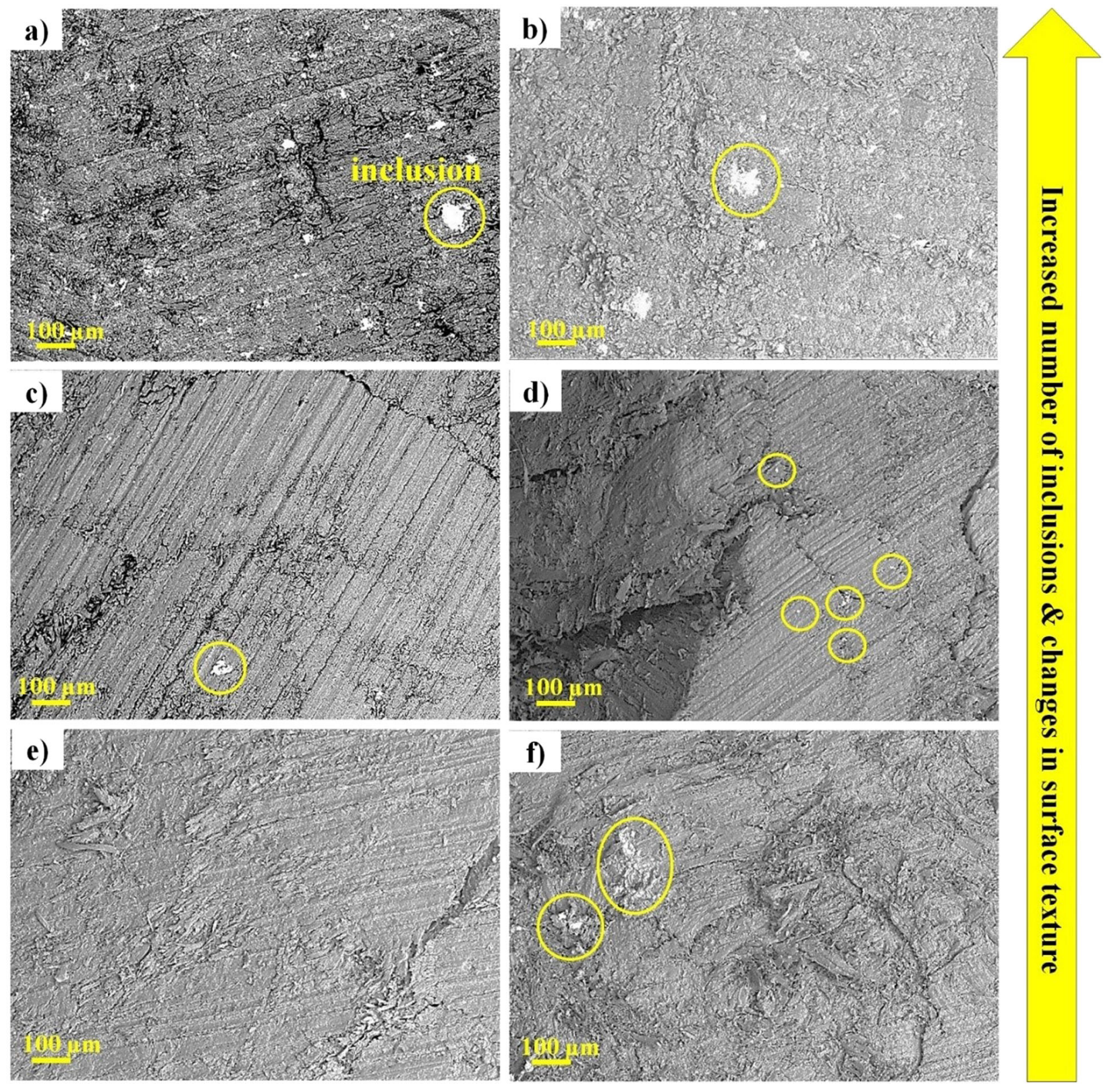

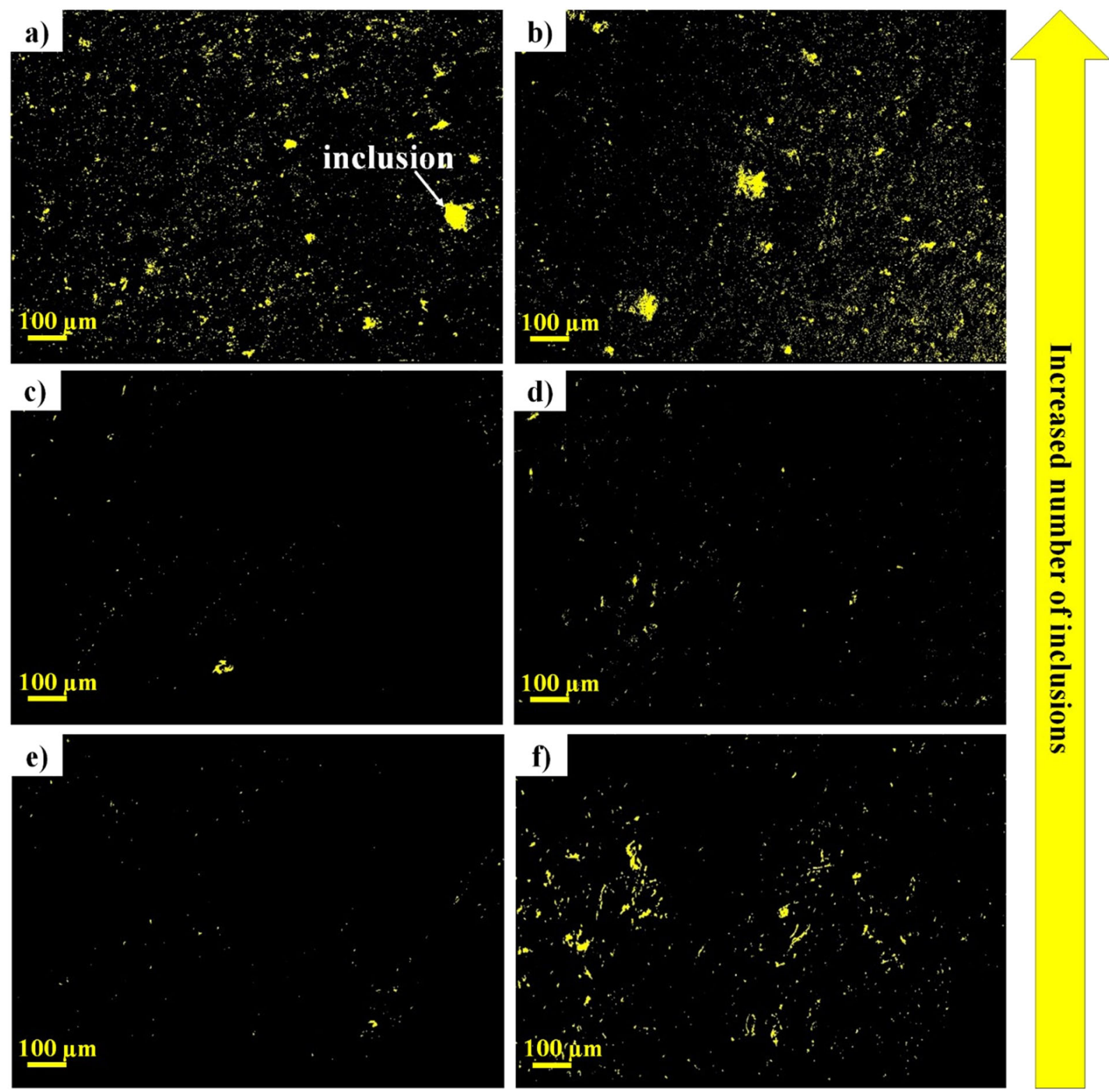

Fig. 5 Image analysis of SEM images of samples \#4 at region $\mathbf{1}$ before and after storage. a, b Torrefied pellet (tor_sample4) before storage (a) and after 1 month of storage (b). c, d Wood pellet type I (wp1_sample4) before storage (c) and after 1 month of storage (d). e, f Wood pellet type II (wp2_sample4) before storage (e) and after 1 month of storage (f). Yellow colour indicates the inclusions detected at the surface of the samples.

storage, wood pellets type II inclusions got enriched in $\mathrm{Si}, \mathrm{Mg}$, and $\mathrm{K}$. As expected, torrefied pellets were the most resistant to chemical changes due to the nature of its hydrophobic structure $^{29}$. We also observe a decrease of $10 \%$ in the oxygen content in the organic matrix of all pellets after 1 month of storage. This suggests that pellets suffer oxygen-induced degradation, leading to an increase of oxygen-based inclusions, which is consistent with results presented in Fig. 5.

EDS analysis of inclusions at the surface of biomass pellets. Before storage, inclusions at the surface of all samples are, in average, consisting of major elements such as $\mathrm{C}>\mathrm{O}>\mathrm{Fe}>\mathrm{Si}>\mathrm{Ca}$ for torrefied pellets, $\mathrm{C}>\mathrm{O}>\mathrm{Si}>\mathrm{Ca}>\mathrm{N}$ for wood pellets type I, and $\mathrm{C}>\mathrm{O}>\mathrm{Ni}$ for wood pellets type II. Minor elements found in the inclusions of torrefied pellets, wood pellets type I and II are $\mathrm{Zn}>\mathrm{K}>\mathrm{N}>\mathrm{Mg}>\mathrm{Cu}, \mathrm{Cu}>\mathrm{Cl}>\mathrm{Zn}>\mathrm{K}>\mathrm{Fe}>\mathrm{S}$, and $\mathrm{Fe}>\mathrm{Ca}>$ $\mathrm{Si}>\mathrm{Mg}>\mathrm{S}$, respectively.
After 1 month of storage, inclusions in wood pellets type I and II (Fig. 6d, f) got mainly enriched in Fe (1453\%) and Si $(296 \%)$. Si is mostly found in biomass as amorphous silica $\left(\mathrm{SiO}_{2}\right)^{22}$, while in ash, $\mathrm{Si}$ and $\mathrm{Fe}$ are mostly found as glass, silicates, and oxyhydroxides ${ }^{30}$. We ascribe this large increase in concentrations to the untreated fibers of wood pellets, which are more prone to moisture sorption (M2) than the reacted organic material of torrefied pellets, which have a lower pore $\operatorname{size}^{29}$. Enrichment of Si and Fe is also consistent with increased size of inclusions observed from SEM images (Fig. 5d, f). Image analysis of these SEM images indicates an increase in the average maximum area of the inclusions in wood pellets type I and II (Supplementary Tables 5, 6). During thermochemical conversion, Si- and Fe-bearing glass, silicates and oxyhydroxides can increase ash yield, enhance abrasion-erosion, decrease combustion efficiency and increase operation costs for handling of ashes ${ }^{27}$. The enrichment of $\mathrm{SiO}_{2}$ at the surface of the pellets can also lead to a decrease of thermochemical fuel 
a

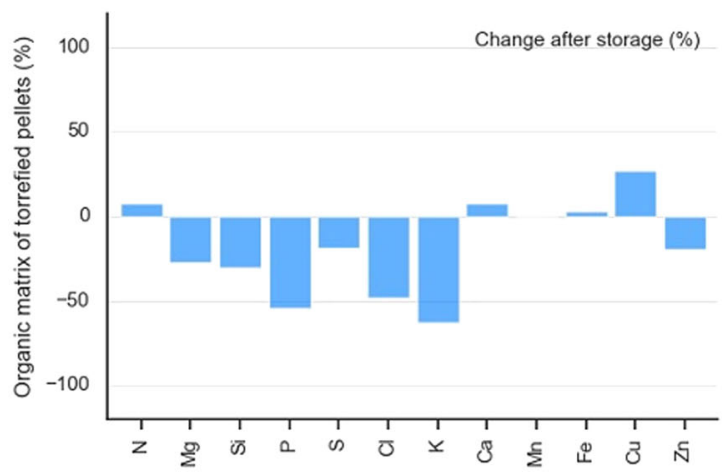

$\mathrm{c}$

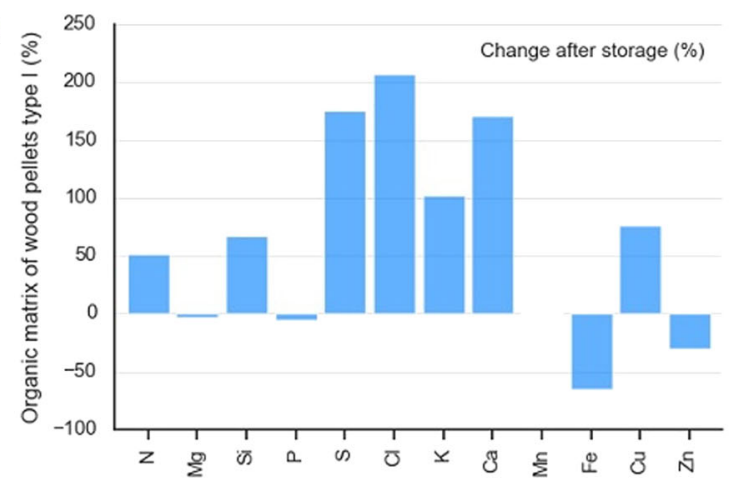

e

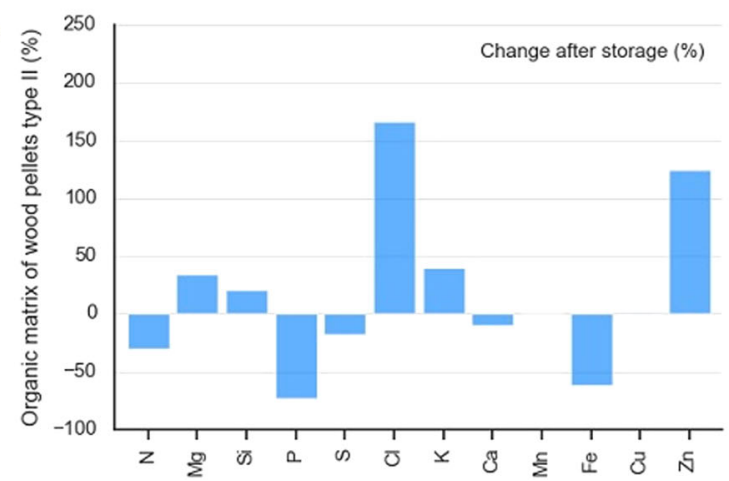

b

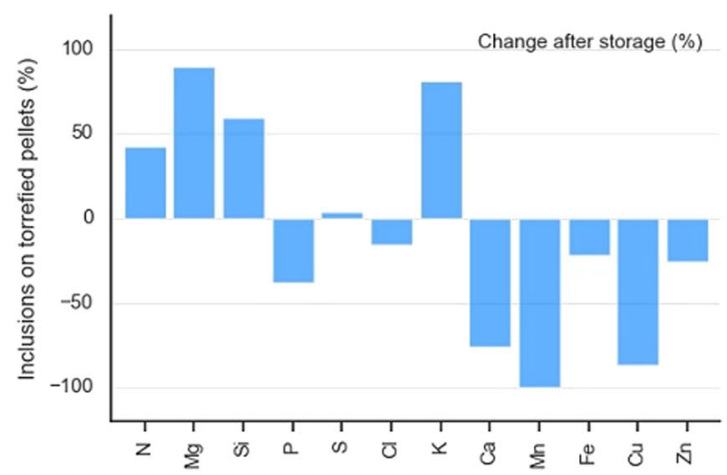

d

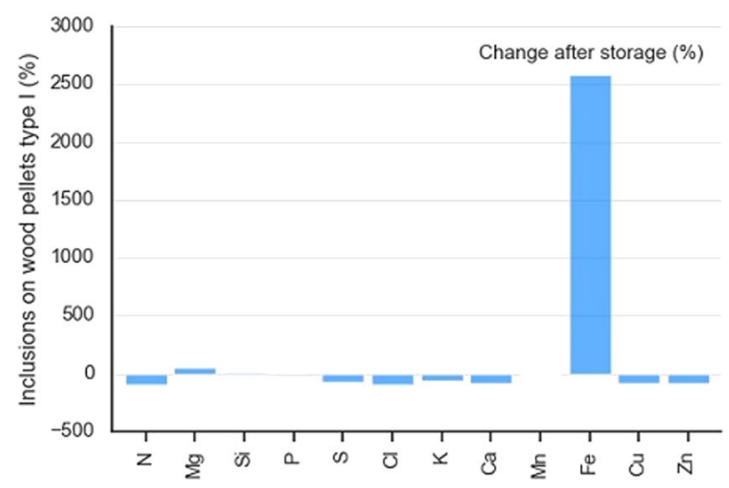

$\mathrm{f}$

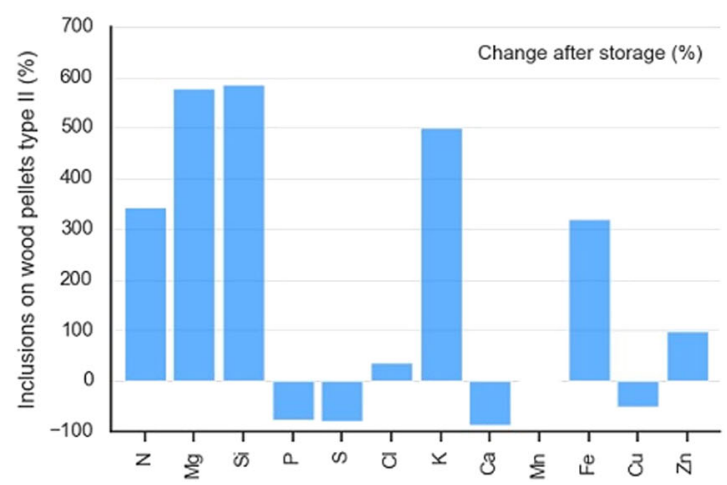

Fig. 6 Percentage change of mean elemental concentrations of the matrix and surface inclusions of biomass pellets after 1 month of storage. a

Organic matrix of torrefied pellets. $\mathbf{b}$ Inclusions on torrefied pellets. c Organic matrix of wood pellet types I. d Inclusions on wood pellets type I. e Organic matrix of wood pellet type II. $\mathbf{f}$ Inclusions on wood pellets type II. Light blue bars represent the mean elemental concentration of each element detected at the surface of the samples.

conversion rates, due to the low melting temperature of silicates, which might encapsulate the remaining char ${ }^{25}$. Additionally, when moisture is adsorbed by the pellets, free hydroxyl ions $\left(\mathrm{OH}^{-}\right)$coupled with alkali cations $\left(\mathrm{K}^{+}\right.$ and $\mathrm{Ca}^{2+}$ ) might react with siliceous phases ${ }^{31}$. The reaction products are water-insoluble compounds based on calcium, alkalis and dissolved silica, leading to inclusion growth due to a concentration gradient through biomass pores ${ }^{31}$. A similar phenomenon has already been observed in concrete ${ }^{32}$.

Regarding minor inorganic-forming elements, after 1 month of storage, inclusions in all pellets got enriched in $\mathrm{Mg}$, followed by $\mathrm{K}$, except in wood pellets type I. These elements are known to be present in the organic structure as $\mathrm{Mg}-\mathrm{K}$ oxalates $^{33}$ and carbonates $^{22}$, while in ash in the form of glass, silicates, carbonates, oxyhydroxides, sulphates, and phosphates ${ }^{27}$. Either at the solid matrix or at the inclusions, increases in the concentration of $\mathrm{Mg}$ and $\mathrm{K}$ are associated with increased inclusion body formation. This is the result of the mobile nature ${ }^{30}$ of these elements, agglomeration, and moisture sorption.
Enrichment of $\mathrm{K}$ after storage could be attributed to the formation/enlargement of K-silicates ${ }^{27}$. In the case of torrefied pellets, K-silicates could already have been formed during thermal pretreatment ${ }^{34}$. Low melting temperature of K-silicates leads to increased ash deposition and fouling ${ }^{35}$. Furthermore, in biomass combustion processes, $\mathrm{K}$ can be released as vapor species, which can further react with other gas components to form $\operatorname{slag}^{36}$. On the other hand, $\mathrm{Mg}$ after storage can be present as dolomite $\left(\mathrm{CaMg}\left(\mathrm{CO}_{3}\right)_{2}\right)^{26}$ or $\mathrm{MgO}^{37}$, which can cause heat exchanger fouling through increased alkali devolatilization ${ }^{36}$.

After 1 month of storage, EDS indicates a decrease in Ca content from major to minor constituent for torrefied samples and wood pellets type I. Meanwhile, in wood pellets type II, Ca decreases from minor to trace element. As explained above, a carbonatation from $\mathrm{Ca}(\mathrm{OH})_{2}$ could have diluted the average concentration of $\mathrm{Ca}$ in the inclusions of all samples ${ }^{26}$.

Lastly, each of the EDS detected elements in inclusions have different surface energy that could lead to agglomeration (M4). Inclusions with lower surface area tend to agglomerate into larger 
inclusions to reduce their surface energy ${ }^{38}$. This rearrangement also leads to creation or expansion of cracks.

Micro-CT scans of biomass pellets: porosity and inclusion growth mechanism. Given the tortuous nature of the cracks within the pellets, we used micro-CT to gain insight into the porosity, development of inclusions, cavities and crack formation and growth during storage. Micro-CT provides advantages compared to conventional microscopy, which is not effective at quantifying buried crack formation away from the pellet surface (Fig. 3). Figs. 7, 8 show the $3 \mathrm{D}$ images of the porosity and inclusions along the sample of 4-mm length from the top to the bottom of the pellets. Values of the porosity and inclusion-topellet volume ratio for each of the pellets are given in Supplementary Table 7. Detailed 3D representation of porosity evolution and inclusion formation, growth, and agglomeration, as a function of storage time, is provided in Supplementary Note 6 and Supplementary Movies 1-3.

Results of the CT scans confirm our hypothesis regarding the reduction in the apparent crack depth after storage (Fig. 3). Due to the tortuous nature of the cracks within the pellets and the increased inclusions at the surface and within the pellets after 1 month of storage, the light from the microscope does not penetrate deep (enough) into the biomass fibres, restricting the application of digital microscopy in crack imaging seriously. CT scans show that although wall fibres expand within the pellets, the void space is higher after one month of storage.

Storage at $40{ }^{\circ} \mathrm{C}$ and $85 \% \mathrm{RH}$ produces changes in the internal porous structure of the pellets. The porosity of the torrefied pellets, wood pellets type I and type II increased by $35 \%, 66 \%$, and $59 \%$, respectively, after 1 month of storage. Our findings confirm previous experiments and support the suggestion ${ }^{9}$ that the volume of the pellet expands as a result of moisture sorption (M2) during high humidity storage (85\% RH). This phenomenon could lead to decreased bulk density and reduced pellet strength ${ }^{9}$. Furthermore, the void space within the pellets can be filled by entrapped air, water molecules and gaseous compounds $\left(\mathrm{CO}_{2}\right.$, $\mathrm{CO}, \mathrm{CH}_{4}$, and volatile organic compounds $)^{8,15}$ released from decomposition of biomass during storage. All these compounds fill the pre-existing cracks and expand them, producing a tortuous 3D network of cracks. The findings presented in Figs. 7, 8 add to observations made by Strandberg et al. ${ }^{25}$, who reported enlargement of cracks and internal cavities during devolatilization of biomass pellets. Internal cavities and cracks can affect the conversion rates by increasing active char oxidation surface ${ }^{25}$. Thus, storage degradation could enhance char oxidation by further increasing gas transport to and from the pellet.

Although we did not monitor off-gassing from stored pellets, there is a large difference between the weight change estimated from porosity calculations and the weight change estimated from weight measurements (Supplementary Note 7 and Supplementary Table 9). This difference in weight implies that pellets are not only absorbing moisture but there are also off-gassing emissions. Gases denser (aldehydes and ketones) ${ }^{8}$ than moist air are known to be present in the off-gassing of biomass pellets during storage. For example, volatile organic compounds, such as acetaldehyde and propanal, which have densities two orders of magnitude higher than moist air.

Furthermore, the resulting highly porous structure exposes a higher surface area of pellet fibers to interact with the surrounding medium during storage. This phenomenon leads to increased oxidation ${ }^{8,15,39}$ accelerating pellet degradation. Examples of the consequences are reduced mechanical durability $^{18}$, decreased calorific value $e^{40}$, increased microbial activity ${ }^{41}$, increased risk of self-ignition ${ }^{8,42}$, and gas concentrations that can exceed occupational standards for worker exposure ${ }^{43}$. Potential solutions to reduce oxidation, moisture sorption and off-gassing during storage are the use of antioxidants ${ }^{42}$ or hydrophobic coatings ${ }^{44}$ during pellet production.

Changes in porosity are in agreement with weight measurements, which report that after one month of storage, torrefied samples, wood pellet type I and type II, increased in average $2.8 \%$, $2.7 \%$, and $2.8 \%$, respectively, compared to their initial weight (Supplementary Note 2). Weight change is also in agreement with measurements of pellet diameter (Supplementary Table 2). Results of the statistical analysis indicate that the two pairs of variables, weight-diameter and porosity-diameter, have a strong positive correlation with a $p$ value less than 0.01 (Supplementary Note 8).

A volume increase of the inclusions within the internal cavities also leads to expansion of cracks (Fig. 8 and Supplementary Movie 3). After 1 month of storage, the inclusion-to-pellet volume ratio increased in torrefied pellets by $38 \%$, in wood pellets type I by $800 \%$ and in wood pellets type II by $310 \%$, with respect to the ratio calculated for pellets before storage. Increased inclusion growth can also be attributed to the presence of rubbery amorphous polysaccharides which are responsible for mineral ion transport (M4). Especially at high humidity, such as the one used in this work; amorphous polysaccharides pass through a moisture-induced glass transition inside the wood cell wall layers which facilitates the diffusion of chemicals ${ }^{45}$. Thus, our findings support this hypothesis that moisture-softened polysaccharides facilitated the growth of inclusions at $40{ }^{\circ} \mathrm{C}$ and $85 \%$. To complement the results presented on Figs. 7, 8, Supplementary Movies 1-3 show how the enlargement of inclusions affect the structure of the pellet and increased cracks.

Conclusion. Our results suggest that significant degradation of biomass pellets was proven due to storage conditions at $40{ }^{\circ} \mathrm{C}$ and $85 \% \mathrm{RH}$. We show that the creation and expansion of cracks in pellets is tightly linked to the increased porosity, regained moisture content, higher inclusion body formation and inclusion agglomeration as a result of extended storage of 1 month. After 1 month of storage, the damaged area with respect to the total area of the front surface of all pellets (area ratio) increased in average by $5 \%$.

To the best of our knowledge, no other authors have quantified the microstructural changes occurring in pellets during storage. Quantification of crack formation and inclusion body formation at the surface and within the pellets is obtained with the use of micro-CT. Results indicate that the increase in the inclusion-topellet volume ratio can be as high as $800 \%$ in wood pellets after one month of storage. As described in previous sections, inclusion growth is the result of multiple mechanisms (M1-M5). Although mechanical properties, such as durability are important to understand the behavior of pellets as a bulk, inclusion formation and agglomeration within the pellets should be studied to optimize fine particulate emissions, thermochemical conversion and fuel particle modeling. Inclusion agglomeration may affect large-scale thermochemical conversion processes, such as centralized district heating and biomass co-firing. On the other hand, pellets with a higher number of cracks at the surface and within the structure are more sensitive to degradation during storage, possibly resulting in revenue loss to companies and consumers as part of the material could be lost. To the extent of discouraging the use of biomass pellets and slowing down the bioenergy transition. Our results challenge existing local and international certifications to develop new standards for handling, transport and storage of biomass pellets. Creation of stronger policies to avoid degradation of pellets could help to reduce breakage, reduce off-gassing and increase pellet conversion efficiency. 

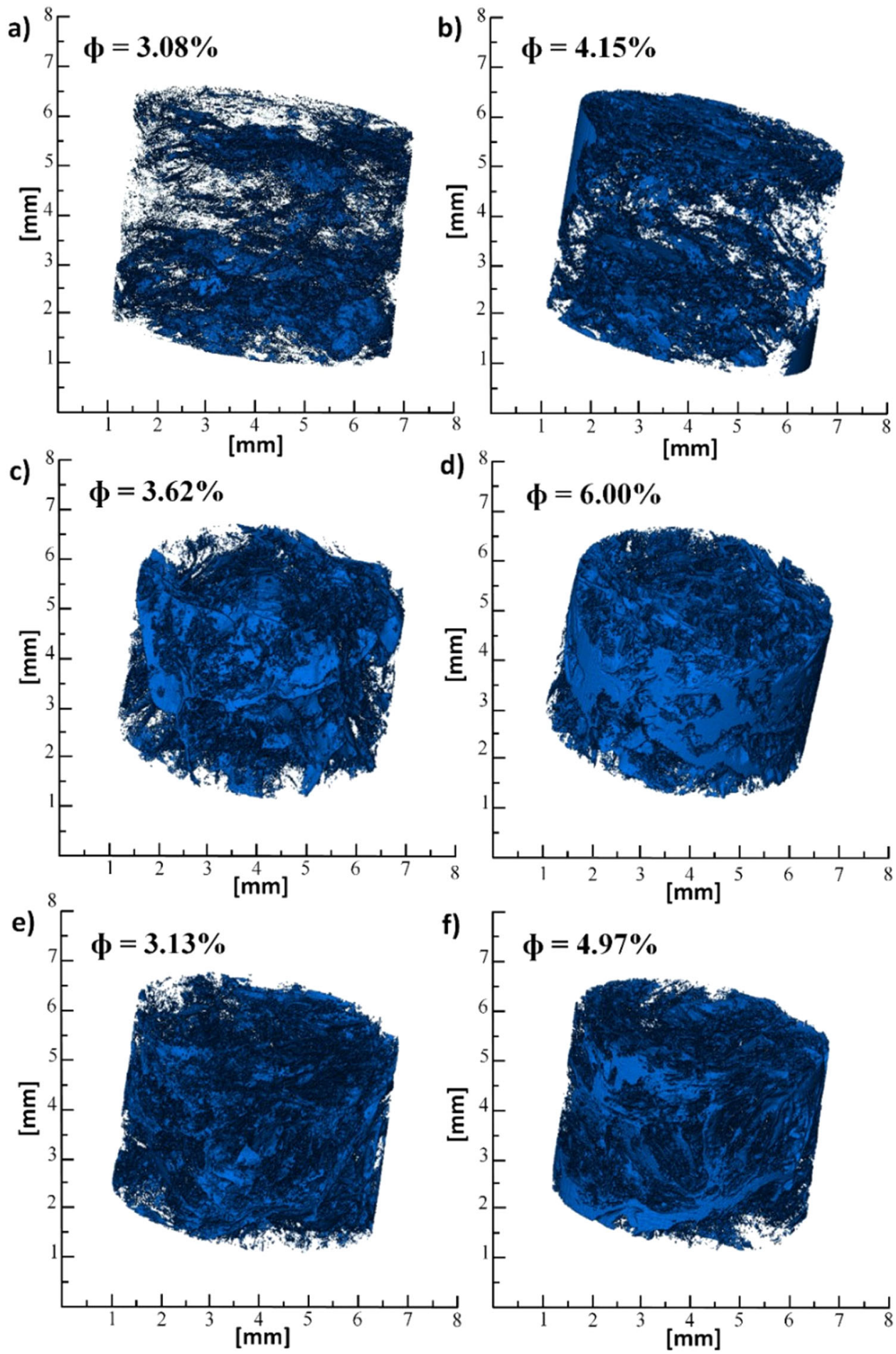

Fig. 7 3D images of porosity $(\boldsymbol{\Phi})$ in samples \#3 before and after storage. $\mathbf{a}$, $\mathbf{b}$ Torrefied pellet (tor_sample3) before storage (a) and after 1 month of storage (b). c, d Wood pellet type I (wp1_sample3) before storage (c) and after 1 month of storage (d). e, f Wood pellet type II (wp2_sample3) before storage (e) and after 1 month of storage (f). Blue colour represents 3D porosity. Percentages shown in the figure indicate the porosity of the samples expressed in \%. See Supplementary Table 7 for detailed information on porosity calculations.

\section{Methods}

Experimental techniques. In the present work the following techniques were used to characterize the degradation of biomass pellets before and after storage: weight and diameter change, digital microscopy, scanning electron microscopy equipped with energy dispersive X-ray spectroscopy (SEM-EDS), and X-ray micro-computed tomography (micro-CT). Morphological changes at the pellet surface were monitored using digital microscopy. SEM-EDS analysis was carried out at the surface and at the cross section of the pellets for better understanding of the changes in morphology and elemental composition of pellets, due to storage. Then, micro-CT was used to characterize the pellet structure using high lateral resolution $3 \mathrm{D}$ images.

Sample. In this work, we monitored two types of untreated commercial white wood pellets, wood pellet type I (wp1) and wood pellet type II (wp2), and one type of torrefied wood pellets (tor). Wood pellets were made from sawdust and purchased from local stores in the Netherlands. No information regarding the manufacturing process was provided. The torrefied pellets were obtained from a 

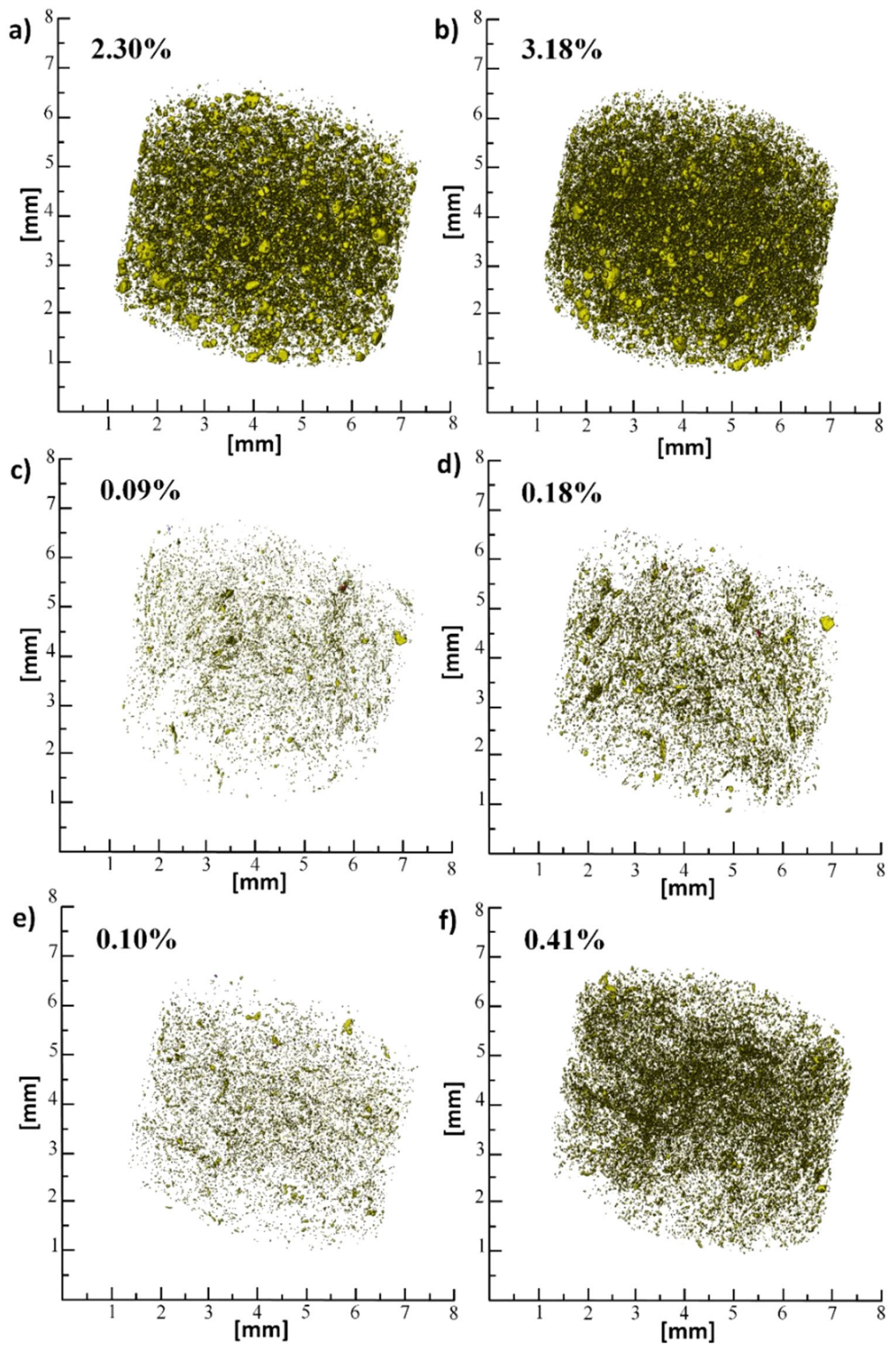

Fig. 8 3D images of inclusions in samples \# $\mathbf{3}$ before and after storage. $\mathbf{a}, \mathbf{b}$ Torrefied pellet (tor_sample3) before storage (a) and after 1 month of storage (b). c, d Wood pellet type I (wp1_sample3) before storage (c) and after 1 month of storage (d). e, f Wood pellet type II (wp2_sample3) before storage (e) and after 1 month of storage (f). Yellow colour represents 3D inclusions. Percentages shown in the figure indicate the inclusion-to-pellet volume ratio expressed in \%. See Supplementary Table 7 for detailed information on inclusion-to-pellet volume ratio calculations.

pilot-scale production facility in the UK and no information about the origin of the pellets and production process was disclosed. The main characteristics of the studied pellets based on ultimate and proximate analysis are provided in Supplementary Note 1 . Samples were stored in a climate chamber $(C+10 / 600$ Climate Test Chamber) with a volume of $600 \mathrm{~L}$ for a period of one month at a constant condition of $40{ }^{\circ} \mathrm{C}$ and $85 \% \mathrm{RH}$. These conditions were selected since they represent typical conditions of transatlantic transportation (from North America to Europe $)^{8,46}$. Furthermore, at and above this temperature and $\mathrm{RH}$ value, deterioration ${ }^{9,11}$ and off-gassing ${ }^{8}$ have proven to be significant in the degradation of biomass pellets. The temperature and relative humidity inside the chamber were kept constant all the time and monitored continuously. We did not investigate higher storage temperatures because, at industrial level, temperatures above $60^{\circ} \mathrm{C}$ are already a concern and then cooling is needed through mechanical ventilation ${ }^{16}$. During the storage period, pellets were examined at 3 sample dates: 0 days, 2 weeks, and 1 month. A detailed description of the characterization and analytical techniques used to carry out this study are described in the following sections. 
The as-received properties such as proximate and ultimate analysis, weight, diameter, surface morphology, and microstructure of the pellets before storage are given as the benchmark for assessment and comparison. Therefore, any changes in the pellet properties after storage can be compared to the as-received properties.

Weight and diameter of pellets. An electronic balance (Sartorius Practum 124-1 $S$ analytical) was used to measure the mass of each pellet at three sampling dates: 0 days, 2 weeks, and 1 month. At the same time, the diameter of each pellet was measured with a Kunzer 7EMS01 digital caliper $150 \mathrm{~mm}$ with an accuracy of 0.01 $\mathrm{mm}$. Data on weight change for all samples are reported in Supplementary Note 2.

Physical changes at the pellet surface. Pre-existing cracks, expansion of preexisting cracks and formation of new ones were quantified using a digital microscope, Keyence VHX- 5000 series, ocular VH-Z100R/W/T. A total of nine samples were examined: three samples per each type of pellet. The notation of these samples is the following: wp1_sample1-3, wp2_sample1-3 and tor_sample1-3. A mark was placed on one side of each sample to ensure that the observation area remained the same during the three sample dates. The damaged surface area at the front face of the pellets was measured using the area measurement built-in function in the digital microscope that allows detection of cracks based on brightness and contrast variations. The front surface of the pellet is defined as the surface facing the lens of the microscope. Besides the pre-existing cracks, pellets contain regions with different surface texture with interparticle gaps and voids result of poor adhesion between adjacent biomass fibers during the pelletization process ${ }^{47}$. The pelletization process also produces regions with fiber ends and particles sticking out of the surface as a result of adhering structures being torn apart ${ }^{47}$. These regions were detected by the microscope as they differ from the pellet material lighter color. In the manuscript such regions and cracks are referred to as "damage". Although large damaged areas were easy to detect automatically, the manual marking mode was used to include small cracks in the computation of the total area of the cracks. The percentage of increase in the damaged area was calculated as the difference between the damaged area after storage and before storage related to the damaged area before storage.

The apparent depth of surface cracks was determined using the built-in tool from the digital microscope to construct a 3D surface profile measurement of the front face of the pellet. The built-in tool is based on photographic stitching combined with a depth composition function and multi-lighting 48 . A line was drawn between two points along the front face of the pellet to get a profile graph of the surface. Three profile lines were drawn along the front face of each sample to ensure repeatability.

Surface and elemental composition analysis. Observations related to the morphology and composition of pellets before and after 1 month of storage were obtained by SEM-EDS. SEM analysis was performed on a JEOL IT100 Scanning Electron Microscope using a backscattered electron detector, coupled with an EDS analyser. Data were processed with the corresponding InTouchScope ${ }^{\text {wit }}$ software. The diameter of the analysed area was a few hundred micrometres and the analysed depth around $1 \mu \mathrm{m}$. EDS measurements were carried at low-vacuum due to the nonconductivity of the samples. Images were recorded in a compositional mode using an accelerated voltage of $10 \mathrm{kV}$ and probe current of $65 \mathrm{pA}$. The cross section of the samples was mechanically ground up to 800 grit with $\mathrm{SiC}$ grinding sandpaper and glued to the sample holder using double-sided tape. Just the side, which was grinded, was taped to the SEM-EDS holder to avoid the detection of Si and C from the grinding paper. A mark was made on one side of each sample to ensure that the observation area remained constant during the three sampling dates. For comparison, SEM was conducted on the cross section of the sample pellets before storage and after one month of storage. We examined six pellets, two samples per each type of pellet and inspected two regions per each sample. The notation of these samples is the following: wp1_sample4-5, wp2_sample4-5 and tor_sample45. In average we selected 4 points per each region per each sample for scanning, on the matrix and on the inclusions. The elemental composition of biomass comprises: major ( $>1 \%$ at.), minor $(1-0.1 \%$ at.), and trace $(<0.1 \%$ at.) elements.

Once the images were taken, all samples were returned to the climate chamber. SEM images were also analysed with the area measurement built-in function of the digital microscope. This method was used to determine the number and area of the inclusions before and 1 month after storage.

3D characterization of biomass pellets. To confirm the previous findings of this study, we used micro-CT scanner (Phoenix Nanotom 180NF) to map the microstructure of the pellets and follow the development of cracks and inclusions in the internal cavities during the storage period. All samples were scanned from the top to the bottom of the pellets, one per each type. The scanned pellet length was 4 $\mathrm{mm}$. Prior to the scanning, each biomass pellet was glued to a cylindrical glass rod. Once the scan was performed, the sample was removed from the glass rod and returned to the climate chamber. Images were taken using X-rays at $90 \mathrm{kV}$ and a $2284 \times 2304$ pixel detector. The voxel size used was between $0.004 \times 0.004 \times 0.004$ $\mu \mathrm{m}$. Image analysis of micro-CT scans and movies were carried out using AVISO software, version 2019.1. To create 3D images of the porosity and inclusions, we reconstructed 4-mm length of the pellets. A segment of $0.7 \mathrm{~mm}$ of pellet length was used for monitoring inclusion growth and for creating Supplementary Movies 1-3.
AVISO software was also used to estimate the porosity of the pellets and the inclusion-to-pellet ratio after different times of storage. Porosity is defined as the fraction of the total volume, which is void (free) space in the pellet. The inclusionto-pellet volume ratio is defined as the ratio of the volume of the inclusions to the total volume of the pellet. Image processing steps comprises image segmentation (quantification and image separation), noise reduction filters, and label analysis to extract statistical and numerical information ${ }^{49}$.

Statistics. In order to determine associations between the storage time, volume expansion, porosity and weight change for all three type of pellets, we used Pearson's correlation analysis and calculated the corresponding $p$ values. After we applied a logarithmic transformation LogWorth to convert relatively small $p$ values into a more readable scale. Detailed statistical analysis is provided in Supplementary Note $8 . P<0.01$ was used to indicate significance.

\section{Data availability}

Data supporting the findings presented in this paper are available within the manuscript and in the Supplementary Material. Datasets for 3D reconstruction of micro-CT images of pellets are available from the corresponding author upon request.

Received: 18 June 2020; Accepted: 29 November 2020; Published online: 04 January 2021

\section{References}

1. Melton, N., Axsen, J. \& Sperling, D. Moving beyond alternative fuel hype to decarbonize transportation. Nat. Energy 1, 16013 (2016).

2. Staples, M. D., Malina, R. \& Barrett, S. R. H. The limits of bioenergy for mitigating global life-cycle greenhouse gas emissions from fossil fuels. Nat. Energy 2, 16202 (2017).

3. Smith, P., Nkem, J. \& Calvin, K. In Climate Change and Land: An IPCC Special Report on Climate Change, Desertification, Land Degradation, Sustainable Land Management, Food Security, and Greenhouse Gas Fluxes in Terrestrial Ecosystems (Intergovernmental Panel on Climate Change (IPCC), 2019).

4. Shankar Tumuluru, J., Sokhansanj, S., Hess, J. R., Wright, C. T. \& Boardman, R. D. REVIEW: A review on biomass torrefaction process and product properties for energy applications. Ind. Biotechnol. 7, 384-401 (2011).

5. Calderón, C. et al. Statistical report 2019: Report Pellet. (2019).

6. Strauss, W. \& Walker, S. Global pellet market outlook in 2018. Canadian Biomass in Canadian Biomass Magazine (Canadian Biomass, 2018).

7. Magelli, F., Boucher, K., Bi, H. T., Melin, S. \& Bonoli, A. An environmental impact assessment of exported wood pellets from Canada to Europe. Biomass Bioenergy 33, 434-441 (2009).

8. Wang, S. et al. Variation in the physical properties of wood pellets and emission of aldehyde/ketone under different storage conditions. Fuel 183, 314-321 (2016).

9. Deng, T., Alzahrani, A. M. \& Bradley, M. S. Influences of environmental humidity on physical properties and attrition of wood pellets. Fuel Process. Technol. 185, 126-138 (2019).

10. Shojaeiarani, J., Bajwa, D. S., Bajwa, S. G., Shirzadifar, A. \& Pandey, P. A numerical model approach to predict moisture absorption in densified solid biomass during storage. Ind. Crops Prod. 140, 111529 (2019).

11. Gilvari, H. et al. The effect of environmental conditions on the degradation behavior of biomass pellets. Polymers 12, 970 (2020).

12. Biswas, A. K., Rudolfsson, M., Broström, M. \& Umeki, K. Effect of pelletizing conditions on combustion behaviour of single wood pellet. Appl. Energy 119, 79-84 (2014).

13. Searcy, E. et al. in International Bioenergy Trade pp. 115-117 (Springer, 2013).

14. Schlünssen, V., Madsen, A. M., Skov, S. \& Sigsgaard, T. Does the use of biofuels affect respiratory health among male Danish energy plant workers? Occup. Environ. Med. 68, 467-473 (2011).

15. Ferrero, F., Malow, M. \& Noll, M. Temperature and gas evolution during large scale outside storage of wood chips. Eur. J. Wood Wood Prod. 69, 587-595 (2011).

16. Dafnomilis, I., Lodewijks, G., Junginger, M. \& Schott, D. Evaluation of wood pellet handling in import terminals. Biomass Bioenergy 117, 10-23 (2018).

17. Ilic, D., Williams, K., Farnish, R., Webb, E. \& Liu, G. On the challenges facing the handling of solid biomass feedstocks. Biofuels Bioprod. Biorefining 12, 187-202 (2018).

18. Graham, S., Eastwick, C., Snape, C. \& Quick, W. Mechanical degradation of biomass wood pellets during long term stockpile storage. Fuel Process. Technol. 160, 143-151 (2017).

19. Graham, S., Eastwick, C., Snape, C. \& Quick, W. Degradation of biomass fuels during artificial storage in a laboratory environment. Int. J. Low Carbon Technol. 7, 113-119 (2012). 
20. Dyjakon, A. \& Noszczyk, T. The influence of freezing temperature storage on the mechanical durability of commercial pellets from biomass. Energies 12, 2627 (2019).

21. Lemaitre, J. \& Dufailly, J. Damage measurements. Eng. Fract. Mech. 28, 643-661 (1987).

22. Vassilev, S. V., Baxter, D., Andersen, L. K. \& Vassileva, C. G. An overview of the chemical composition of biomass. Fuel 89, 913-933 (2010).

23. Goldstein, J. I. et al. in Scanning Electron Microscopy and X-Ray Microanalysis (eds. Goldstein, J. I. et al.) pp. 15-28 (Springer, 2018).

24. Sander, B. Properties of Danish biofuels and the requirements for power production. Biomass Bioenergy 12, 177-183 (1997).

25. Strandberg, A. et al. Biomass pellet combustion: cavities and ash formation characterized by synchrotron X-ray micro-tomography. Fuel Process. Technol. 176, 211-220 (2018).

26. Supancic, K., Obernberger, I., Kienzl, N. \& Arich, A. Conversion and leaching characteristics of biomass ashes during outdoor storage-results of laboratory tests. Biomass Bioenergy 61, 211-226 (2014).

27. Vassilev, S. V., Vassileva, C. G., Song, Y.-C., Li, W.-Y. \& Feng, J. Ash contents and ash-forming elements of biomass and their significance for solid biofuel combustion. Fuel 208, 377-409 (2017).

28. Steenari, B.-M. \& Lindqvist, O. Stabilisation of biofuel ashes for recycling to forest soil. Biomass Bioenergy 13, 39-50 (1997).

29. Tumuluru, J. S. Effect of deep drying and torrefaction temperature on proximate, ultimate composition, and heating value of 2-mm Lodgepole Pine (Pinus contorta) Grind. Bioengineering 3, 384-401 (2016).

30. Vassilev, S. V., Baxter, D., Andersen, L. K. \& Vassileva, C. G. An overview of the composition and application of biomass ash. Part 1. Phase-mineral and chemical composition and classification. Fuel 105, 40-76 (2013).

31. Powers, T. C. \& Steinour, H. H. An interpretation of some published researches on the alkali-aggregate reaction part 1-the chemical reactions and mechanism of expansion. J Am. Concr. Inst. 26, 497-516 (1955).

32. Deschenes, R., Giannini, E., Drimalas, T., Fournier, B. \& Hale, W. Effects of moisture, temperature, and freezing and thawing on alkali-silica reaction. ACI Mater. J. 115, 575-584 (2018).

33. Jong, W. de \& Ommen, J. R. van. Biomass as a Sustainable Energy Source for the Future: Fundamentals of Conversion Processes (John Wiley \& Sons, 2014).

34. Fagerström, J., Steinvall, E., Boström, D. \& Boman, C. Alkali transformation during single pellet combustion of soft wood and wheat straw. Fuel Process. Technol. 143, 204-212 (2016).

35. Lalak, J. et al. Comparison of selected parameters of biomass and coal. Int. Agrophys. 30, 475-482 (2016).

36. Thy, P., Lesher, C. E. \& Jenkins, B. M. Experimental determination of high-temperature elemental losses from biomass slag. Fuel 79, 693-700 (2000).

37. Werkelin, J., Lindberg, D., Boström, D., Skrifvars, B.-J. \& Hupa, M. Ashforming elements in four Scandinavian wood species part 3: Combustion of five spruce samples. Biomass Bioenergy 35, 725-733 (2011).

38. Kocjan, A., Logar, M. \& Shen, Z. The agglomeration, coalescence and sliding of nanoparticles, leading to the rapid sintering of zirconia nanoceramics. Sci. Rep. 7, 1-8 (2017).

39. Wen, C. Metallic Foam Bone: Processing, Modification and Characterization and Properties (Woodhead Publishing, 2016).

40. Graham, S. Degradation of biomass fuels during long term storage in indoor and outdoor environments. (University of Nottingham, 2015).

41. Noll, M. \& Jiriis, R. Microbial communities in large-scale wood piles and their effects on wood quality and the environment. Appl. Microbiol. Biotechnol. 95, 551-563 (2012).

42. Sedlmayer, I. et al. Off-gassing reduction of stored wood pellets by adding acetylsalicylic acid. Fuel Process. Technol. 198, 106218 (2020).

43. Rahman, M. A., Rossner, A. \& Hopke, P. K. Carbon monoxide off-gassing from bags of wood pellets. Ann. Work Expo. Health 62, 248-252 (2018).

44. Whittaker, C. \& Shield, I. Factors affecting wood, energy grass and straw pellet durability-a review. Renew. Sustain. Energy Rev. 71, 1-11 (2017).
45. Jakes, J. E. Mechanism for diffusion through secondary cell walls in lignocellulosic biomass. J. Phys. Chem. B 123, 4333-4339 (2019).

46. Lee, J. et al. The effects of storage on the net calorific value of wood pellets https://doi.org/10.7451/CBE.2015.57.8.5. (2015).

47. Stelte, W. et al. A study of bonding and failure mechanisms in fuel pellets from different biomass resources. Biomass Bioenergy 35, 910-918 (2011).

48. KEYENCE. Digital Microscope VHX-5000. User's Manual. https://www. keyence.com/products/microscope/digital-microscope/vhx-5000/ (2014).

49. Thermo Fisher Scientific. Thermo Scientific Avizo Software 9 User's Guide. https://assets.thermofisher.com/TFS-Assets/MSD/Product-Guides/user-guideavizo-software.pdf (2018)

50. CRU. Climate Research Unit (CRU) datasets. https://crudata.uea.ac.uk/cru/ data/temperature/\#sciref (2014).

\section{Acknowledgements}

This work was supported by the Top Consortium for Knowledge and Innovation for the Biobased Economy under grant TKI-BBE project number BBE-1801. Additional support was provided by the European Union's Horizon 2020 research and innovation programme under the Marie Skłodowska-Curie grant agreement No. 707404 and TKI BioBased Economy project No. 1713 "Biomass pellets: degradation during transport and handling". We would also like to acknowledge W. Verwaal, E. Meijvogel-de Koning for assistance with micro-CT scans measurements, and J.G. van Meel for guidance regarding the $3 \mathrm{D}$ reconstructions of micro-CT data.

\section{Author contributions}

L.C., U.T., and H.G. formulated the research question. L.C. and U.T. designed and performed the experiments, analyzed the data and led the manuscript writing. A.M. and W.d.J. provided suggestions on the experiments and data interpretation. H.G., D.S., A.M., and W.d.J. contributed to editing the manuscript.

\section{Competing interests}

The authors declare no competing interests.

\section{Additional information}

Supplementary information is available for this paper at https://doi.org/10.1038/s43246 020-00113-y.

Correspondence and requests for materials should be addressed to L.C. or W.d.J.

Peer review information Primary handling editor: John Plummer

Reprints and permission information is available at http://www.nature.com/reprints

Publisher's note Springer Nature remains neutral with regard to jurisdictional claims in published maps and institutional affiliations.

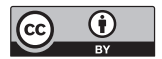

Open Access This article is licensed under a Creative Commons Attribution 4.0 International License, which permits use, sharing, adaptation, distribution and reproduction in any medium or format, as long as you give appropriate credit to the original author(s) and the source, provide a link to the Creative Commons license, and indicate if changes were made. The images or other third party material in this article are included in the article's Creative Commons license, unless indicated otherwise in a credit line to the material. If material is not included in the article's Creative Commons license and your intended use is not permitted by statutory regulation or exceeds the permitted use, you will need to obtain permission directly from the copyright holder. To view a copy of this license, visit http://creativecommons.org/ licenses/by/4.0/.

(C) The Author(s) 2021 